\title{
Standards, Norms, and Best Practices Workgroup Report
}

\author{
Michelle Gluck, Adrian K. Ho, Martin R. Kalfatovic, David Mellor, Louise Page, Brianna Schofield, \\ Emma Wilson
}

\section{Abstract / OSI2017 Workgroup Question}

What standards, norms, best practices, exit strategies, and incentive systems does the world of scholarly communications need? What is the future ideal? What will it take (including studies or pilots) to develop a better understanding of how the scholarly communication system works now? This workgroup will also necessarily touch on norms and definitions, so will include discussions as warranted about open and impact spectrums as covered in OSI2016.

\section{Introduction}

Standards improve efficiency by reducing the number of times in which one is expected to alter their normal workflow. Researchers who use standard practices in dissemination quickly learn how to navigate through the process. Journals, editors, and publishers who use standard practices quickly become more efficient at decision making, evaluation, and then dissemination.

However, in order to prevent the stifling of innovation, standards creation requires planning for iterative improvement. Furthermore, there is no "one size fits all" that can reasonably accommodate diverse and decentralized communities. Scholarship, both the process of systematic knowledge creation in the sciences and humanities and the process of knowledge dissemination, both relies on current evidence and is highly decentralized, which presents particular challenges for the creation and adoption of standards within this community. Organizations such as the
National Information Standards Organization (NISO) exist to address this particular challenge and will perhaps be required to in order to achieve the goals presented below.

The purpose of this workgroup and its report is to identify existing relevant standards, evaluate areas of overlap or perhaps conflict, which can be used to foster increased collaboration, and areas where relevant standards do not yet exist, which can be used to focus future effort.

\section{Open Scholarship: Idea Gen- eration to Dissemination}

As a threshold matter, the Standards Workgroup approached the concept of "open scholarship" as much broader than a focus on open access to scholarly articles alone. Instead, the Workgroup conceptualized open scholarship as applying transparency to all applicable aspects of the research lifecycle: idea generation, research design, data collection, data analysis, early dissemination, peer review, 
contributorship, funding sources, and dissemination of research products such as journal articles, research data, and software codes. Though some stages of the research lifecycle are not applicable to all fields of scholarship, increasing transparency into any relevant products will engender similar benefits to those disciplines as transparency does to every other discipline. More openness is necessary at all stages, with appropriate protection for sensitive data and with the associated costs fairly shared among stakeholders in the interest of mutual benefits.

Making all aspects of the scholarly workflow more transparent is increasingly necessary in order to foster trust and collaboration in the process of knowledge creation and sharing. Society demands and deserves accessible insight into the foundation of knowledge because of scholarship's central role in policy-making, among other areas. Creating a more transparent scholarly ecosystem requires rethinking how each individual and institution is rewarded and recognized for their roles in knowledge creation and dissemination, so that transparency becomes a key metric of success and accountability. Furthermore, it requires careful attention in order to design a system that is sustainable, just, and responsive to new evidence.

\section{Need to Align Standards}

Competing standards threaten to derail their benefit. Just as learning how to use a new piece of software takes time, competing standards threaten to confuse the wider community. However, as stated above, overly rigid standards stifle improvement, and so in many cases the best practice is to standardize a framework of policies and actions so that each stakeholder can quickly ascertain their meaning. In this sense, the wider community can "speak the same language" while permitting necessary diversity in actual policy.

A reasonable example of this need is the four Data Sharing Policy Types used by Springer Nature and the relevant data transparency policies presented in the Transparency and Openness Promotion (TOP) Guidelines. While similarly structured, the four specific "types" or "levels" described are slightly unaligned. While realignment may be difficult, it could provide immediate benefit to a wider community.

Possible areas of contention in such an alignment could be the use of specific terminology. "Type" does not convey value, rigor, or potential challenges with a particular policy, whereas the term "Level" does. Depending on one's point of view, it could be either beneficial or detrimental to convey such values in policy types. Perhaps simple labels that describe the essence of each type or level would alleviate this tension (e.g. Encourage, Disclose, Require, and Verify), though that is slightly more challenging to convey than a simple numbering system.

\section{Proposed OSI Guiding Prin- ciples}

In order for OSI to continue to make progress and generate action items that advance its mission, while still being able to function with a consensus model among stakeholders who have very diverse interests, we must agree on a set of principles to use when making future decisions. The "What Is Open" Workgroup" 
from OSI 2016 laid out most of the salient principles and we propose that OSI endorse it as a collective. When future proposals are considered, this common set of principles will guide OSI and enable its members to judge the potential effect of any action. In brief, those principles highlight that openness can be considered as a spectrum across four dimensions: Discoverability, Accessibility, Reusability, and Transparency (DART). Any proposal can be assessed on its (estimated) impact on the openness of the practices along the research lifecycle, e.g., idea generation, knowledge creation, interpretation and analysis, dissemination, and evaluation.

We propose that one additional dimension be considered: Sustainability. While not directly related to open scholarship, financial sustainability is necessary for any proposal to be adopted or for any adopted proposal to be implemented for mediumand long-term use. Since persistence of a research output is an unmentioned but essential element for later discoverability, accessibility, and reusability, adding Sustainability to the DART principles (hereinafter referred to as "DARTS") aligns with the underlying principles proposed in 2016.

The principle of Sustainability requires that proposals consider the method by which content will be hosted and curated and services be supported. In some cases, proposals could include sustainability plans that rely on existing funding sources (e.g., government, foundation, or NGO support) but without incurring an increase in such reliance (or ideally with a decrease in such reliance). Alternatively, proposed projects could be sustainable if a reasonable business plan be created that increases any dimension of DART.
This proposal needs to be assessed by key stakeholders present in OSI. As of now, there is no decision-making framework adopted by OSI. As such, the natural course of action is to either 1) propose that the following motion be considered "adopted" only after affirmation from every delegate who chooses to participate in a vote conducted by the planning committee or 2) the proposal be shelved until a governing and decision-making framework is adopted.

Proposed: The Open Scholarship Initiative envisions a scholarly community where all parts of the research lifecycle are openly available. In order to achieve this vision, OSI adopts the following principles in order to evaluate policy proposals and actions: research products must be made more Discoverable, Accessible, Reusable, Transparent, and Sustainably supported. Policies that increase openness among one or more of these dimensions, while having no net decrease on any other, are aligned with the mission and purpose of OSI delegates and member institutions.

\section{Making DARTS a Reality}

One way of approaching this challenge, and what we're proposing herein, is to encourage widespread adoption of the DARTS framework. Connecting the entire research workflow will help to ensure that the body of work, from idea dissemination, data collection, interpretation, dissemination, and evaluation increase along every dimension of DARTS.

The Open Science Framework (OSF https://osf.io) is designed both for those scholarly activities and for the DARTS dimensions. As a key to its utility in con- 
necting a preserving a complex research workflow, its open source code and APIs allow for connections to other research tools. The fact that it is open source and its endowment for 50 years of maintenance address important sustainability questions. Its public content is discoverable through the SHARE initiative (https://share.osf.io/), which not only makes work on the OSF Discoverable and Accessible, but also makes research outputs from other repositories connected.

Utilization of this and related tools will help make a truly open scholarly community happen. This will take additional education, marketing, and coordination between players.

\section{Open Standards Matrix}

The Standards, Norms, and Best Practices workgroup envisions that a fruitful path forward to operationalizing this proposal is to build upon a draft "open standards matrix" initiated by the Workgroup in 2017. Still in the nascent stage, the matrix aims to identify potential standards and best practices that can increase openness. (It is to be evaluated in accordance with the DARTS principles.) The matrix lists stakeholders across columns (i.e., funders, researchers, universities, libraries, societies, and publishers) and stages of the research lifecycle across rows (i.e., idea generation, knowledge creation, interpretation and analysis, dissemination, and evaluation). See the complete matrix here.

Standards, Norms, and Best Practices to Promote Openness in Scholarship

\begin{tabular}{|c|c|c|c|c|c|c|}
\hline & Funders & Researchers & Universities & Libraries & Societies & Publishers \\
\hline Idea generation & Registries. & $\begin{array}{l}\text { Open data. Regis- } \\
\text { tries }\end{array}$ & & & $\begin{array}{l}\text { Networking \& } \\
\text { ECR creation. } \\
\text { Topic \& discipline } \\
\text { specific standards. } \\
\text { Registries. }\end{array}$ & \\
\hline $\begin{array}{l}\text { Knowledge } \\
\text { creation }\end{array}$ & & & $\begin{array}{l}\text { Institutional } \\
\text { recognition/ } \\
\text { rewards for col- } \\
\text { laboration and/or } \\
\text { sharing, } \\
\text { Increase transpar- } \\
\text { ency. }\end{array}$ & & & \\
\hline $\begin{array}{l}\text { Interpretation \& } \\
\text { analysis }\end{array}$ & & $\begin{array}{l}\text { Use of tools to } \\
\text { address bias and } \\
\text { motivated reason- } \\
\text { ing. }\end{array}$ & & & & $\begin{array}{l}\text { Versions; open } \\
\text { licensing to enable } \\
\text { reuse and innova- } \\
\text { tion. Open peer } \\
\text { review. Best } \\
\text { practices pro- } \\
\text { posed } \\
\text { COPDESS by } \\
\text { http://www.copd } \\
\text { ess.org/copdess- } \\
\text { suggested-author- } \\
\text { instructions-and- } \\
\text { best-practices-for- } \\
\text { journals/. }\end{array}$ \\
\hline Dissemination & Open Science & Pre-prints. & Data repositories & Repositories & & SSO, SEO, DOI, \\
\hline
\end{tabular}




\begin{tabular}{|c|c|c|c|c|c|c|}
\hline & Funders & Researchers & Universities & Libraries & Societies & Publishers \\
\hline & $\begin{array}{l}\text { linked to ROI } \\
\& \quad \text { societal } \\
\text { impact; Funder } \\
\text { expectation of } \\
\text { open access. }\end{array}$ & & $\begin{array}{l}\text { \& archiving; } \\
\text { Open Access; } \\
\text { Recognition of } \\
\text { researchers' roles } \\
\text { (contributorship); } \\
\text { Open Science } \\
\text { linked to ROI and } \\
\text { societal impact. }\end{array}$ & $\begin{array}{l}\text { connected } \\
\text { through open } \\
\text { APIs. Taxono- } \\
\text { mies. Workshops } \\
\text { and training for } \\
\text { dissemination. }\end{array}$ & & $\begin{array}{l}\text { portable submis- } \\
\text { sion, device ag- } \\
\text { nostic, PDF, } \\
\text { JATS, OAI-PMH, } \\
\text { machine read, } \\
\text { common stand- } \\
\text { ards for interop- } \\
\text { erability, taxono- } \\
\text { mies, mineable. }\end{array}$ \\
\hline Evaluation & $\begin{array}{l}\text { Standards and } \\
\text { metrics that } \\
\text { align w/ scien- } \\
\text { tific ideals. }\end{array}$ & $\begin{array}{l}\text { Post-pub peer } \\
\text { review. }\end{array}$ & $\begin{array}{l}\text { Hiring \& promo- } \\
\text { tion based on } \\
\text { open practices. }\end{array}$ & $\begin{array}{l}\text { Surface metrics } \\
\text { created by funders } \\
\& \text { societies. }\end{array}$ & & $\begin{array}{l}\text { Surface metrics } \\
\text { created by funders } \\
\text { and societies. } \\
\text { Data citation. }\end{array}$ \\
\hline
\end{tabular}

Table 1. Proposed standards and best practices to increase openness.

The workgroup began to identify potential "standards," "norms," and "best practices" to populate the cells of the matrix. ${ }^{1}$ For example, to increase openness, funders may require Creative Commons licensing of works at the dissemination stage and publishers may make research outputs machine-readable. The Standards, Norms, and Best Practices workgroup expects that with additional time and input from stakeholders with a wider range of expertise, this open standards matrix may prove a useful starting point to indicate areas where individual stakeholders can contribute to increasing the openness of research products.

One area that requires additional development is the creation of standards in knowledge creation. In particular, researchers, societies, and publishers can work together to start to address current needs, such as those that relate to open data.

\section{1}

https://docs.google.com/presentation/d/1Yk_tu 4blfkJpPHyfIt9uuCF8jVXvoNDhdmhjTNSnTG M/edit?usp=sharing

\section{Open Data}

Mentioned above, both Springer Nature's Data Policy Types and the TOP Guidelines lay out modular data sharing policies and provide some examples and resources for each level. There is still need, however, to increase standardization of how each of those types/levels are operationalized.

Standardized data disclosure statements would help researchers quickly select the statement that applies to them, and aid in later meta-analytic work in evaluating openness.

Standardized exceptions to data sharing mandates would have similar benefits (though would likely still require free response, "other reasons"). Reasonable ethical constraints, the use of intellectual property concerns may or may not be a reasonable exception to some funders and publishers, and inability to share massive data sets could all be considered.

The meaning of peer review is still not well defined when it comes to any object that is not a traditional paper. Setting standards or options for such review practices is needed. As a suggestion, various tiers of data peer review could be used: 
verification of the data's existence, verification that reasonable meta-data or a "data dictionary" are included, basic assessment that the data set is complete, and finally the ability to computationally reproduce the results are different tiers that could be applied.

Other members of the Open Scholarship Initiative should address the missing standards presented in this gap analysis and highlight known gaps as they are identified.

\section{Summary and Next Steps}

The use of standardized best practices for making scholarship more Discoverable, Accessible, Reusable, Transparent, and Sustainable will help to make the vision of OSI a reality. The following actions, described above in detail, are the recommended next steps toward this process:

- Adopt a unifying policy goal in order to evaluate future proposals at OSI.
- Coordinate alignment between closely related open data policy frameworks.

- Facilitate the creation of best practices and specific policy frameworks for detailed actions relating to open data.

- Solicit help in identifying existing standards within the Open Standards Matrix so that gaps represent truly actionable items.

- Coordinate with stakeholders who are working on similar standards alignment within the open science community, for example the Data policy standardization and implementation interest group at the Research Data Alliance.

- Advocate for tools that make every part of the research workflow more connected, efficient, and preserved, such as the Open Science Framework.

\section{Standards, Norms, and Best Practices Workgroup:}

Michelle Gluck, Associate General Counsel, George Washington University Adrian K. Ho, Director of Digital Scholarship, University of Kentucky Libraries Martin R. Kalfatovic, Associate Director, Smithsonian Libraries David Mellor, Project Manager, Journal and Funder Initiatives, Center for Open Science Louise Page, Publisher, PLOS

Brianna Schofield, Executive Director, Authors Alliance Emma Wilson, Director of Publishing, Royal Society of Chemistry

\section{End Notes}

1. http://osinitiative.org/osi-reports/osi2016-reports/report-from-the-what-is-openworkgroup/ 